\title{
Research on pre-scientific concept of light in children's cognitive activity
}

Zhigao Lan, Yang Yu, Dan Yan, Shulin Yang

Zhigao Lan, Yang Yu, Dan Yan, Shulin Yang, "Research on pre-scientific concept of light in children's cognitive activity," Proc. SPIE 10452, 14th Conference on Education and Training in Optics and Photonics: ETOP 2017, 104525S (16 August 2017); doi: 10.1117/12.2269882

SDIE Event: 14th Conference on Education and Training in Optics and Photonics, ETOP 2017, 2017, Hangzhou, China 


\title{
Research on Pre-scientific Concept of "Light" in Childen's Cognitive Avtivity
}

\author{
Lan Zhigao ${ }^{\mathrm{a}}$, Yu Yang ${ }^{\mathrm{a}}$, Yan Dan ${ }^{\mathrm{a}}$, Yang Shulin ${ }^{\mathrm{a}}$ \\ ${ }^{a}$ School of Electronic Information, Huang Gang Normal College, Huang Zhou, Hu Bei, \\ 438000
}

\begin{abstract}
Based on the theory of Ausubel's meaningful learning and cognitive characteristic of childen's pre-scientific concept, two students of Huang Gang Middle School have been interviewed continuously about cognition of interaction between light and matter. Comprehension degree of childen's pre-scientific concept about interaction between light and matter has been deeply understood, formation of strategy of childen's pre-scientific concept has been discussed.Several influence factors related to formation of childen's pre-scientific concept have been analyzed ,such as sex, family environment and learning experience of kindergarten and primary school.
\end{abstract}

Keywords: pre-scientific concept, light, childen, cognition

\section{Introduction}

Pre-scientific concept is the existing cognition and experience of childen before any specific content education, it's the initial state of formation of childen's scientific concept, it's also the basic of building scientific concept and the key factor of realizing concept change.For physicists, light is material entity which emitted from light source and transmits in the space. Light will interact with objects in the propagation path and emerge some observable phenomenons. Then, what is light for childen? People recognize surrounding world achieve useful information and form scientific concept of light,

14th Conference on Education and Training in Optics and Photonics: ETOP 2017, edited by Xu Liu,

Xi-Cheng Zhang, Proc. of SPIE Vol. 10452, 104525S · (c) 2017 ICO, IEEE, OSA, SPIE

CCC code: $0277-786 X / 17 / \$ 18 \cdot$ doi: $10.1117 / 12.2269882$

Proc. of SPIE Vol. 10452 104525S-1 
this progress is achieved absolutely in virtue of vision.It's interesting to understand how scientific concept of light forms in childen's mind.Through long-term interview of two students of Huang Gang Middle School, it's discovered that there exists obvious difference about understanding of light of childen and explaination of optical phenomenon before and after systematic learning of optical knowledge. Pre-scientific concept varies remarkably in this progress.

\section{Introduce of interview object}

The interview object of research is two ninth grade students of Huang Gang Middle School(Hui Hui and Han Han), specific situation is shown in table 1 .

Table 1. The basic situation of interview object

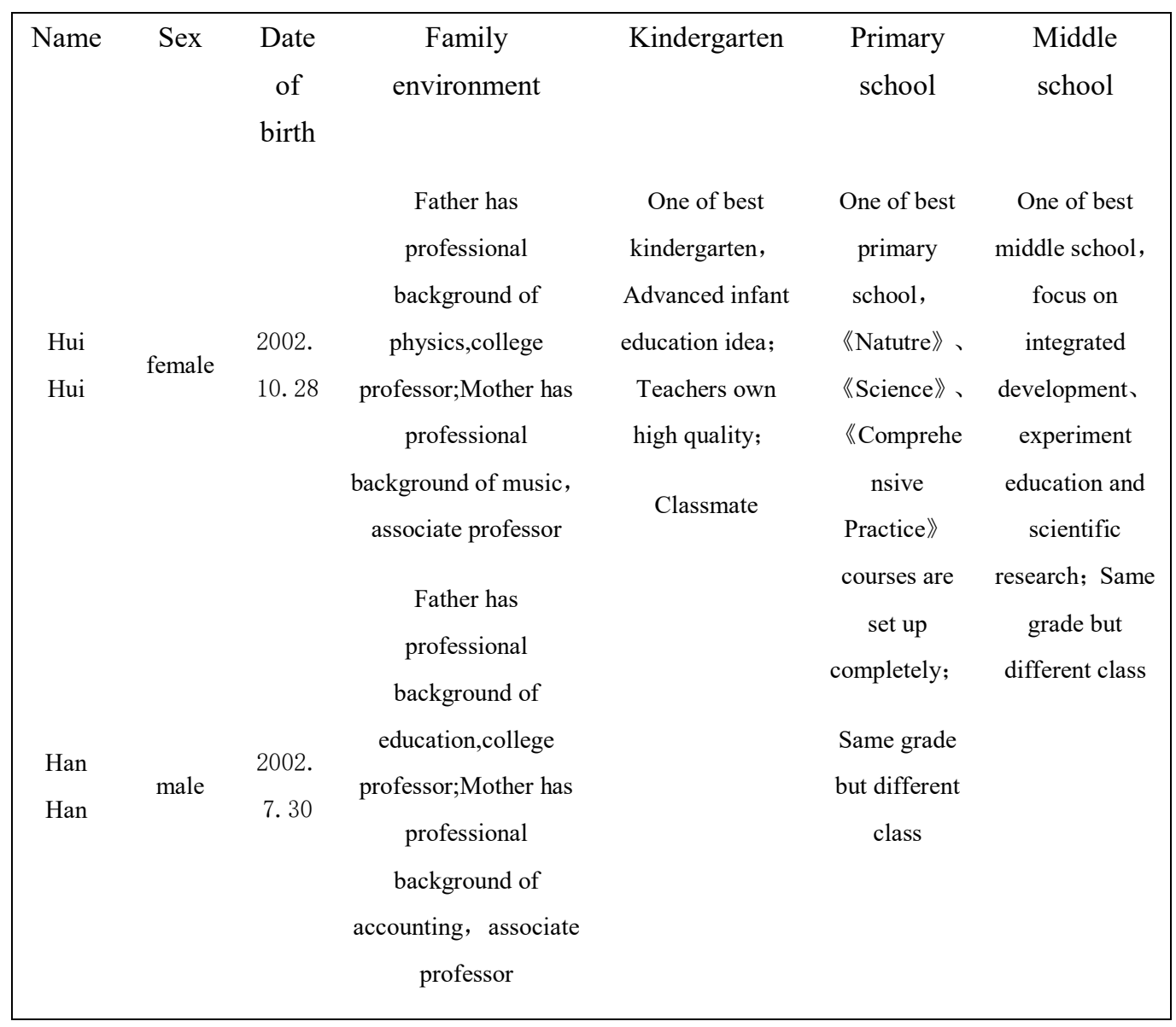


The first author of this paper is Huihui' father who has been doing the study of scientific education and researches

for a long time ${ }^{[1-3]}$. Huihui and Hanhan live in the same community and they communicate frequently after classes since their kindergarten and primary times.

\section{Interview of contents and results}

We have refereed the researches of light in the second chapter ${ }^{[4]}$ in our previous study before the interview. Then, the topic of our talk mainly focused on two themes: 'what is the light?' and 'the interaction between light and other materials'.

\section{(1) 'what is the light ?'-'Light - mass in the space'}

Interviewer: Where is the light in the house? (The interview was conducted in daytime on the middle of June of 2014.)

Huihui: The house is filled with the light.

Hanhan: There is sunshine everywhere.

Interviewer: Where is the light in the house? (The interview was conducted in daytime on the middle of December of 2016.)

Huihui: The house is filled with the light.

Hanhan: There is sunshine everywhere.

The answers of both the young children might be close to the answers of physicist. However, we doubted that it was possible to propose a concept that 'Light - mass in the space'which is completely satisfied by the physicists.

And we also asked the children to explained what the shadow is and how does the shadow form. Then the answers of both the two children are interesting: 
Huihui: When the light is emitted, it will make the obstacle it meets light. But the light can not pass through it, the obstacle is dark, namely the shadow.

Huihui has said something about the formation mechanism of the shadow. She though that the light is one of the masses moving through the space (emitting, meeting, and passing through) and explained that the shadows is formed through preventing the light passing through the obstacle.

In three years, Huihui was interviewed for several times. And the process of his improvement is quietly interesting. When he just graduated from the primary school, he was first interviewed. The interviewer put a piece of paperboard in the middle of the light irradiation path, and then asked him: "what will happen to the light ? Hanhan (12 years old)

answered : The light would disappear because when you you put the paperboard there, it will block the propagation of light and make the light be taken nearer, just like the wall in the propagation way. The disappearance of the light arises from the existence of paperboard, resulting in the formation of shadow.

His answer built the correct relationship between the present of paperboard and the disappearance of light. However, he did not take account into the concept of 'light-maas in the space', nor did explain the formation mechanism of shadow. Two and a half years later, Hanhan (14 years and a half)first reflected the idea that the light moved in the space when he explained the formation of the shadow on the table.

He said that if you take the cardboard away, the light will return to the table. And if you put the cardboard back into place, the light will not pass through the paperboard. Therefore, the table must be in the shadow of light.

After the explained above, he added immediately something like 'Light - effect' and 'Light - state'.

The light...was hidden in the shadow, it become the shadow of the cardboard, as he added.

HanHan has made objective progress in the two and a half years. The concepts, 'Light - effect'and'Light - state', do not disappear when he acquires the concept of 'light - maas in the space'. He has holed these three ideas, and always transferred between the various ideas.

Proc. of SPIE Vol. 10452 104525S-4 


\section{(2) Light and its interactions with matter}

(a) Magnifying glasses

With a magnifying glass, paper can be ignited in the sun. And most children between the ages of 11 and 14 have had some attempts like this phenomenon. How do they explain that?

Han Han: Magnifying glass can enlarge the object. You use magnifying glass to magnify light, so the paper is heat up. If you leave it there for a while, it will burn. I think the reason is magnifying glass can magnify light, so there have a lot of light.

Cong Cong: I guess the reason is magnifying glasses can focus the sun's rays.

Interviewer: I think you are right. Can you draw a picture to explain it?

Cong Cong: Because Light is more or less hot......

Interviewer: OK, draw a picture and tell me where the sun is, and where should we put the paper and magnifying glass.

Cong Cong: For example, the sun is here and paper is there. The sun's rays scatter around. The magnifying glasses can focus the sun's rays on a tiny little point (shown in figure 1).

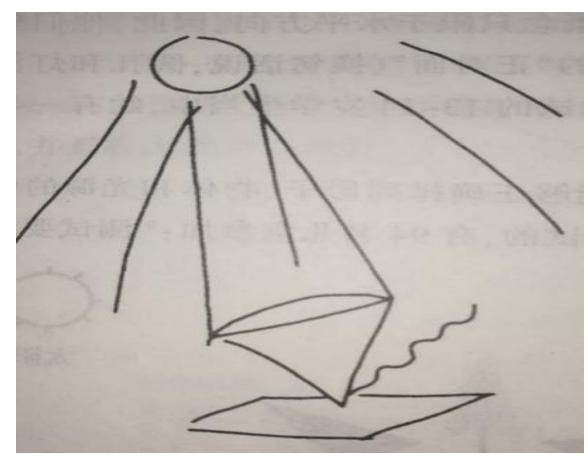

Figure 1. A magnifier ignites paper

Interviewer: Is there more sunlight behind the magnifying glass than front of? 
Cong Cong: No. The sunlight is more concentrated behind the magnifying glass. The magnifying glass focus the sun's rays on a tiny little point on the paper and actually start a fire.

Actually, the two answers are the same. The first answer is the magnifying glass can enlarge the light. The second answer is the magnifying glass can focus the sun's rays on a tiny little point.

(b)Light reflection

When Han Han and Cong Cong were in Grade Six in 2014 and in Grade Nine in 2016, we tested out their understanding of light reflection respectively.

Test results in sixth grade:

In sixth grade most children have no concept of light reflection. They also don't know the concept of light is the actual object.

Interviewer:Is there any light on the mirror?

Han Han:Yes.

Interviewer:How does it origin from?

Han Han: Actually there is no light. It's just a reflection of the light. There is no light on the mirror. If you put the mirror in front, the light reflects in the mirror. You can say there's another light behind the mirror.

Han Han only has said the concept of light source which is a image behind the mirror.

Test results in ninth grade:

Contrary to the above result, in ninth grade most children have concepts of light reflection and light is the actual object. 


\section{Conclusion:description of light-education of optics}

\section{(1) Science education begins with core concept}

Pre-scientific concept of children is characterized by individual differences incoherence and stability. In early stage of children's life, they gradually develop some science concept、knowledge and skills through exploring surrounding world. The description of light has always been accompanied by the growth of children. In preschool stage, science concept、knowledge and skills of children develop rapidly, the importance of science development in preschool stage can not be underestimated, because it will have a profound impact on scientific development in the future. Lots of recent research of children's learning style are based on Ausubel's meaningful learning theory. In Ausubel's meaningful learning theory ${ }^{[5]}$, early idea of children is considered very important, it's the base of development of scientific concept. Therefore, teachers must set up the situation of scientific investigation, it's significant for children to form pre-scientific concept. In this research, sex has no significant influence on the form of pre-scientific concept, but good family education and favorable teaching resources of kindergarten and primary school are beneficial for constructing pre-scientific concept.

\section{(2) Description of light}

In above discussion, two distinct concepts of light have been shown. Light is considered as light source and light phenomenon in the first concept, while in the second concept light is considered as independent entity that exists in the space. First concept can't help children understand light phenomenon accurately, while second concept indicates obvious progress. The key reason is that children have learned content of interaction between light and matter in eighth grade.Scientific inquary is an effective to construct scientific concept.

\section{(3) Development of children and teaching of optics}

Obviously, children can successfully change from first concept to second concept.Actually, most of children(10-11) are accustomed to accept the first concept,while most of children(13-14) are accustomed to accept the second concept. Children can't change from one concept to another soon, old concept can't automatically disappear from children's mind.It's the precondition of exploring optical problems that distinguish concept of light from light source or light effect and establishing concept of light in the space.In many countries, junior school students have learned optics 
courses. Teachers should evaluate students' understanding degree of concept of light in the space.If students have not established this concept or can't utilize this concept systematically, then their main learning goal is obtaining this concept.After children obtaining this concept, they usually endow the entity of light in space with some properties, but it's not completely consistent with physicists' model. There are several learning stages from pre-concept to scientific concept, the effect of designing and selecting experiments is obvious.

\section{REFERENCE}

[1] Lan Z G and Yang C Q, “Research on preconception in taeching of physics,"Journal of higher correspondence education(natural science).Papers 14(1), 21-23(2001).

[2] Lan Z G and Wan X L, "Explanation for the law of inertia from the perspective of falsificationism," Journal of Wuhan university of science and technology(social science edition).Papers 11(1),33-36(2009).

[3] Lan Z G and Wan X L, "Research on teaching content of the law of inertia" Curriculum,teaching material and method.Papers 31(2), 101-106(2011).

[4] Liu X L(translation), Driver, R., Guesne,E. and Tiberghien, A.,[Children's Ideas in Science],ShangHai Science and Technology Education Press,ShangHai, 9-31(2008).

[5] Zhu F, Zhu J L(translation), Johnston,J.,[Early Explorations in Science],ShangHai Science and Technology Education Press,ShangHai, 25(2008). 